\title{
Investigation on effect of fibre hybridization and orientation on mechanical behaviour of natural fibre epoxy composite
}

\author{
P KALIAPPAN ${ }^{1}$, R KESAVAN $^{1, *}$ and B VIJAYA RAMNATH ${ }^{2}$ \\ ${ }^{1}$ Department of Production Technology, M.I.T. Campus - Anna University, Chromepet, Chennai 600 044, India \\ ${ }^{2}$ Department of Mechanical Engineering, Sri Sairam Engineering College, Chennai 600 044, India \\ *Author for correspondence (kesavan@mitindia.edu)
}

MS received 15 June 2016; accepted 2 September 2016; published online 25 July 2017

\begin{abstract}
Nowadays bio fibre composites play a vital role by replacing conventional materials used in automotive and aerospace industries owing to their high strength to weight ratio, biodegradability and ease of production. This paper aims to find the effect of fibre hybridization and orientation on mechanical behaviour of composite fabricated with neem, abaca fibres and epoxy resin. Here, three varieties of composites are fabricated namely, composite 1 which consists of abaca fibre and glass fibre, composite 2, which consists of neem fibre and glass fibre, whereas composite 3 consists of abaca, neem fibres and glass fibres. In all the above three varieties, fibres are arranged in three types of orientations namely, horizontal (type I), vertical (type II) and $45^{\circ}$ inclination (type III). The result shows that composites made up of abaca and neem fibres with inclined orientation $\left(45^{\circ}\right)$ have better mechanical properties when compared with other types of composites. In addition, morphological analysis is carried out using scanning electron microscope to know the fibre distribution, fibre pull out, fibre breakage and crack propagation on tested composites.
\end{abstract}

Keywords. Neem fibre; abaca fibre; hybrid composite; hand layup process; mechanical properties; morphological analysis.

\section{Introduction}

The drastic development in the area of material research makes us to find new materials that may replace conventional materials used in automotive, marine and aerospace applications. The new material should be eco-friendly, biodegradable, recyclable, high strength to weight ratio, nontoxic, easily available and machinable. Hence, the composite materials are developed using natural fibres, polymers and metals to fulfil the above desired properties.

Sawsen et al [1] stated that flax fibres absorb water during the mixing stage and release it gradually during the curing stages, which result in disturbance of rheological properties. In addition, the diametrical shrinkage of the fibre in the desorption stage can lead to a weakening of the fibrematrix bond. Hence, they suggested that treatment of the fibre and/or cement mixture is necessary to prevent the fibre-matrix debonding. Liang et al [2] analysed the tensiontension fatigue behaviour of flax fibre reinforced epoxy matrix composites. Sparnins et al [3] found a new method of interfacial shear strength valuation, based on the length distribution of fibres pulled out from the tensile fractured surface of a flax-reinforced composite with vinyl ester and acrylated epoxidized soy oil resin matrices. El-Shekeil et al [4] studied the influence of fibre content on mechanical, morphological and thermal properties of kenaf fibres reinforced poly(vinyl chloride)/thermoplastic polyurethane poly-blend composites and found that thermal degradation took place in three steps, as in first step, composites as well as the matrix had a similar stability. Although in second step, matrix showed a slightly better stability than the composites, but in the last step, composites showed a better stability than the matrix.

Sawpan et al [5] investigated the mechanical properties of chemically treated random short fibre and aligned long hemp fibre reinforced PLA composites over a range of fibre content $(0-40 \mathrm{wt} \%)$. They found that tensile strength, Young's modulus and impact strength of short hemp fibre reinforced PLA composites increased with increase in fibre content. Alkali and silane fibre treatments improve tensile and impact properties due to good fibre-matrix adhesion and increased matrix crystallinity. Mahjoub et al [6] conducted a study to find out the effects of different conditions of alkaline treatment in terms of the concentration of alkali solution and immersion time on the fibre properties and found that fibre treatment improves mechanical properties. Anuar and Zuraida [7] reported that the elastomer composite reinforced with 20 volume percentage of kenaf fibre improves mechanical properties, which is due to the interaction between matrix systems and kenaf fibre.

Sapuan et al [8] conducted tensile and flexural tests on natural fibre composite materials (Musaceae/epoxy) and found a very stable mechanical behaviour of the composites under different tests. This made many researchers to develop an adequate system for producing a good quality of woven banana fibre composite, which may be used for household utilities. Hamzaoui et al [9] studied the mechanical performance of 
modified mortar using hemp fibres under various processing conditions. Vijaya Ramnath et al [10] fabricated and evaluated the mechanical behaviour of hybrid natural fibre composite using jute and abaca fibres along with glass fibres. They concluded that the hybrid composite has better mechanical strength than mono fibre composite. Pothana et al [11] conducted the dynamic mechanical analysis of banana fibre reinforced polyester composites with a special reference to the effect of fibre loading, frequency and temperature. The intrinsic properties of the components, morphology of the system and the nature of interface between the phases determine the dynamic mechanical properties of the composite.

Li et al [12] developed an experimental programme based on the statistical method of fractional factors design and found that the compressive and flexural properties could be modelled using a simple empirical linear expression based on statistical analysis and regression, and that the hemp fibre content (by weight) was the critical factor affecting the compressive and flexural properties. Aziz and Ansell [13] studied the effect of alkalization and fibre alignment on the mechanical and thermal properties of kenaf and hemp bast fibre composites. Sellami et al [14] investigated two types of treatments for fibres to assess their efficiency. The first treatment was extracting the sugars by distillation of the fibres followed by water proofing the Diss fibres to prevent water absorption. The compressive and flexural strength parameters of Diss-cement composite were used to assess the treatment performances. Azwa et al [15] evaluated the characteristics of several natural fibre composites exposed to moisture, thermal, fire and ultraviolet (UV) degradation through an extensive literature review. The effects of chemical additives such as fibre treatments, fire retardants and UV stabilizers were also addressed and they have also concluded that the optimum fibre content provided strength in a polymer composite, but it also became an entry point for moisture attack.

Ravi Sankar et al [16] discussed about the composite made up of natural fibres like banana, borassus, jute and sisal and gave a brief explanation of advances and characterization of new set of natural fibre composites. Moothoo et al [17] studied the potential of flax tows in composite processing as an alternative to flax spun yarns. Bledzki et al [18] studied the mechanical properties of PLA composites with man-made cellulose and abaca fibres. They observed that tensile strength and stiffness were increased by 1.45 and 1.75 times, respectively. Reinforcing with abaca fibres ( $30 \mathrm{wt} \%$ ) enhanced both Young's modulus and tensile strength by 2.40 and 1.20 times, respectively. Rahman et al [19] chemically treated abaca with benzene diazonium salt to improve the mechanical properties of the abaca-polypropylene (PP) composites. The surface morphologies of the fracture surfaces of the composites were recorded using a scanning electron microscope (SEM) and revealed that interfacial bonding between the treated filler and the matrix significantly improved by treating abaca, which lead to better dispersion of the filler into the matrix. Liu et al $[20,21]$ studied the effect of microstructure of natural fibre on the transverse thermal conductivity of unidirectional composite, fabricated by resin transfer moulding technique and also investigated the effect of mercerization and silane treatments on the thermal conduction behaviour of unidirectional abaca fibre-epoxy composite. Bledzki et al [22] assessed the effects of modification of the fibre on the basis of morphology, mechanical and thermal resistance.

Gironès et al [23] evaluated the flexural properties of abaca (Musa textilis)-reinforced PP composites. When comparing mechanical properties of composites reinforced with fibre glass, it shows that the potentiality of abaca-reinforced PP composites were suitable for low impact strength applications. Vijaya Kumar et al [24] investigated tensile and impact strength of neem fibre-reinforced polyester composites and found that neem composite has tensile strength of $24.4 \mathrm{MPa}$ with an impact strength of $0.4 \mathrm{~J}$. Ali et al [25] investigated wear resistance of neem fibre composites and concluded that the wear resistance of the Polyacrylonitrile reinforced neem composites increase due to increase in polyacrylontrile concentration. Mike et al [26] investigated the effect of fibre content and the particle size of polyethylene-based neem fibre composites. They concluded that particle size 21.63 mesh and $40 \mathrm{wt} \%$ filler content at $77.7 \%$ desirability is at an optimum condition, found by response surface method. This condition shows an optimal tensile strength of $14.51 \mathrm{MPa}$, impact strength of $92.31 \mathrm{~kJ} \mathrm{~m}^{-2}$ and hardness of 242.14. From the above review, it has been concluded that the work done on Abaca with neem fibre hybrid composite does not exist and also fabrication of such a hybrid composite have better mechanical behaviour.

Natural fibre composite are renewable, light in weight with good mechanical, thermal and insulation properties, non abrasive and bio degradable. They are a non-health hazard in nature. The main objective of this work is the fabrication of abaca- and neem-based hybrid composite by hand layup process, on which no work has been done so far. As abaca and neem fibres are available abundantly worldwide, utilization of their strength and advantages are extremely essential to develop eco-friendly and pollution-free materials for automotive aero space and outdoor applications. These fibres find applications in filling materials in bolster, trim parts, rack and external semi-structures.

\section{Materials and methods}

In this section, the materials used for fabricating composites namely abaca, neem fibres and the fabrication method of composites are discussed.

\subsection{Fibres used}

Natural fibres are materials that belong to a class of hairlike materials, which are in the form of continuous filaments. They are preferred as reinforcing materials for composites used for automotive and aerospace applications, because they 
are bio-degradable, eco-friendly and available at low cost as well. The examples are plant (vegetable) fibres such as cotton, flax, hemp, abaca, sisal, jute, kenaf, bamboo, coconut, animal fibres from domestic sheep and silk. In this work, neem and abaca fibres are used to fabricate the composites. The neem fibres have high potential as reinforcing fibre in polymer composites that are available at home and grow to a height of 15-25 m. It has properties like reddish brown, easy to work and a pest resistant. Moreover, they have good properties like high tensile modulus, thermal, acoustic and low abrasive. Abaca fibre is obtained from a plant belonging to the banana family that can grow about 12 feet (4 m) tall. In this study, neem fibre with $25 \mathrm{~cm}$ long and $130 \mu \mathrm{m}$ diameter is used to fabricate the composite. In addition, abaca fibre having a diameter of $180 \mu \mathrm{m}$ and length of $2 \mathrm{~m}$ is used. Normally, this fibre is extracted from the trunk of the plant. These fibres are generally used to make twines and ropes, but nowadays it is gaining importance as a good reinforcement for composite materials. A fibre volume fraction of $40 \%(0.4 \mathrm{vf})$ is adopted while fabricating the composite, because it gives good mechanical properties [27].

\subsection{Hand lay up process}

In this work the hand lay up method, which is simple and easy is used for making the composite laminates. The woven or knitted or twisted fibres are impregnated with resin by hands using rollers. Generally, steel rollers are used to impregnate resins, which may be replaced by nip-rollers for better impregnation. In this method, after fabrication of composite, the sample is allowed to cure under standard working temperature. The schematic diagram of hand lay up process is shown in figure 1 .

Here, glass fibre is placed in the mould after spreading the thinner on its surface. Then, resin and hardener mixture are applied on the surface of the glass fibre and the neem fibres are arranged on it. Now the glass fibre is placed on the neem fibre and resin; hardener mixture is spread over it on which again neem fibres are spread. On the top most layer, glass fibre is placed and a weight of $18 \mathrm{~kg}$ is placed on it for $20 \mathrm{~h}$ for complete curing of the composite. The same procedure is repeated for abaca-glass fibre composite and also for abaca, neem and glass fibre hybrid composites. In this work, three types of composites namely type I, II and III

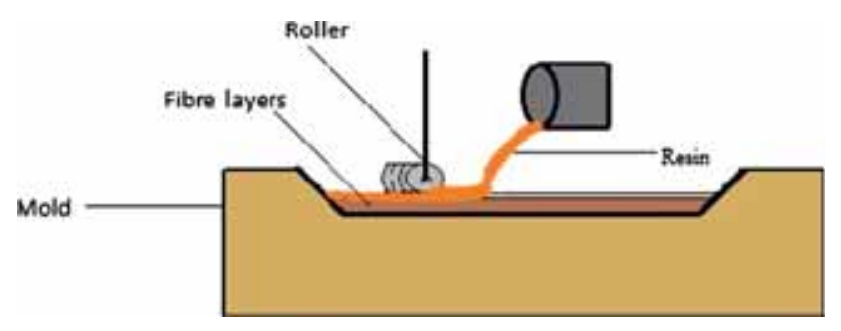

Figure 1. Hand lay up process. are fabricated. Type I composite is fabricated by arranging the fibres parallel to each other in relation with successive layers. Type II composite is fabricated by arranging the fibres perpendicular to each other in relation with successive layers and type III composite is fabricated by arranging the fibres inclined at $45^{\circ}$ to each other in relation with successive layers. In this work, abaca + glass fibre combination is termed as composite 1 , neem + glass fibre combination is termed as composite 2 while abaca + neem + glass fibre is termed as composite 3. All these three types of composites with their arrangement is shown in figure $2 \mathrm{a}-\mathrm{c}$.

\section{Testing of materials}

In this work, testing of composite is done in Omega inspection and analysis laboratory, Chennai which is fully equipped to test and inspect varieties of materials, metals and alloys. Specimens are cut as per ASTM standard with abrasive jet machining process at Ambattur, Chennai.

\subsection{Tensile test}

This test is performed to know the material's tensile behaviour like ultimate tensile strength, break load, displacement and strain rate. The specimen is gripped at both ends of a universal testing machine (UTM), which slowly pulls the piece lengthwise until it fractures. The tensile load is plotted against the material's change in length, or displacement. Then the load is converted to a stress and the displacement is converted to strain. ASTM D-638 standard is used to prepare the composite specimen for testing as shown in figure 3.

\subsection{Flexural test}

The flexural test measures behaviour of materials subjected to simple beam loading, which is also called as transverse beam test. Flexural strength is defined as the maximum stress in the outermost fibre of the composite laminate. Maximum fibre stress and maximum strain are calculated for increments of load. Results are plotted in a stress-strain diagram. In this work, a three-point flexural test was performed by preparing the specimen as per ASTM: D790 standard, which is shown in figure 4. The flexural load is applied at the beam's centre point of composite, which has a span of $150 \mathrm{~mm}$. The load continued till the beam bends and fractures. The breaking load and displacement are noted from which flexural strength and strain are calculated.

\subsection{Double shear test}

In this test, the specimen is inserted in the shear test attachment of a UTM by preparing the specimen as per ASTM: D5379, as shown in figure 5. The load is applied such that the specimen breaks in two or three pieces. If the specimen breaks in two pieces, then it is called single shear when it breaks in three 
(a)

\begin{tabular}{|c|}
\hline GFRP layer \\
\hline Abaca(horizontal orientation) \\
\hline Abaca(horizontal orientation) \\
\hline Abaca(horizontal orientation) \\
\hline GFRP layer \\
\hline
\end{tabular}

\begin{tabular}{|c|}
\hline GFRP layer \\
\hline Neem fibre(horizontal orientation) \\
\hline Neem fibre(horizontal orientation) \\
\hline Neem fibre(horizontal orientation) \\
\hline GFRP layer \\
\hline
\end{tabular}

(b)

\begin{tabular}{|c|}
\hline GFRP layer \\
\hline Abaca(vertical orientation) \\
\hline Abaca(vertical orientation) \\
\hline Abaca(vertical orientation) \\
\hline GFRP layer \\
\hline
\end{tabular}

(c)

\begin{tabular}{|c|}
\hline GFRP layer \\
\hline Abaca $\left(45^{\circ}\right.$ inclination $)$ \\
\hline$A b a c a\left(45^{\circ}\right.$ inclination $)$ \\
\hline$A b a c a\left(45^{\circ}\right.$ inclination $)$ \\
\hline GFRP layer \\
\hline
\end{tabular}

\begin{tabular}{|c|}
\hline GFRP layer \\
\hline Neem fibre (vertical orientation) \\
\hline Neem fibre (vertical orientation) \\
\hline Neem fibre (vertical orientation) \\
\hline GFRP layer \\
\hline
\end{tabular}

\begin{tabular}{|c|}
\hline GFRP layer \\
\hline Neem fibre and abaca(vertical orientation) \\
\hline Neem fibre and abaca(vertical orientation) \\
\hline Neem fibre and abaca(vertical orientation) \\
\hline GFRP layer \\
\hline
\end{tabular}

Figure 2. (a) Type 1 composite (fibres in horizontal orientation), (b) type 2 composite (fibres in vertical orientation) and (c) type 3 composite (fibres in inclined orientation).

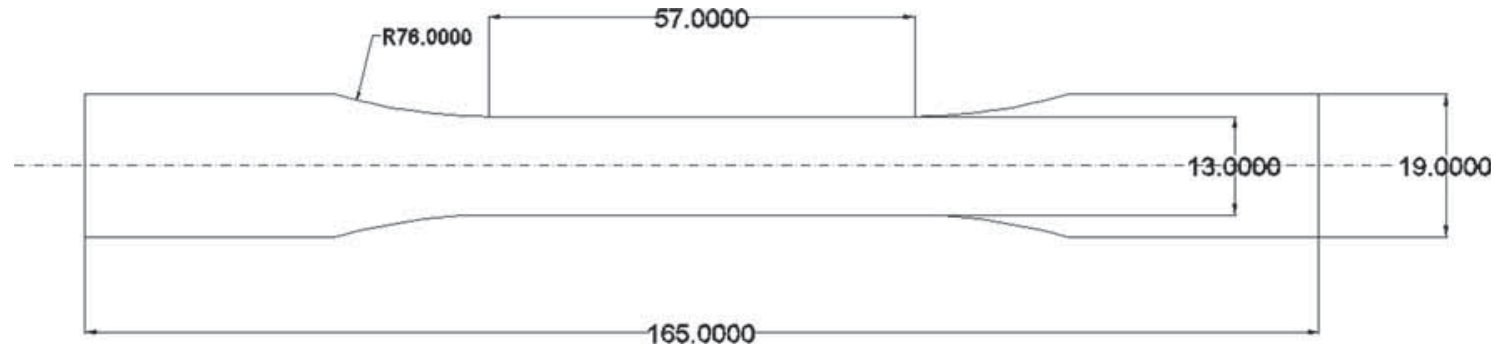

Figure 3. Tensile test specimen (ASTM: D-638).

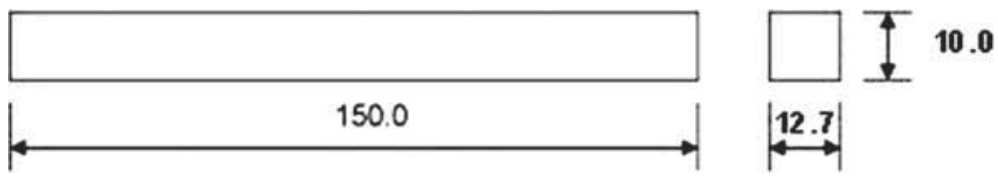

Figure 4. Flexural test specimen.

pieces, then it is called as double shear. In this work, during testing at a particular stage straight fracture occurs, breaking the test piece into three pieces. Maximum load recorded by the pointer is noted, which is known as breaking load along with displacement.

\subsection{Inter-delamination test}

A climbing drum test is a typical peel testing method used to determine the de-lamination characteristics of composite material. By this test, the peel resistance of adhesive bonds with a relatively flexible adherent and the relatively flexible facing of a composite structure is determined. To find the internal mode of failure, the specimen is prepared according to the ASTM: D5528 standard as shown in figure 6. Load is applied in the specimen until it fractures. The break load and displacement are noticed.

\subsection{Impact test}

This test is performed to find the energy absorbed by the composite specimen while dropping a pendulum from an angle of 


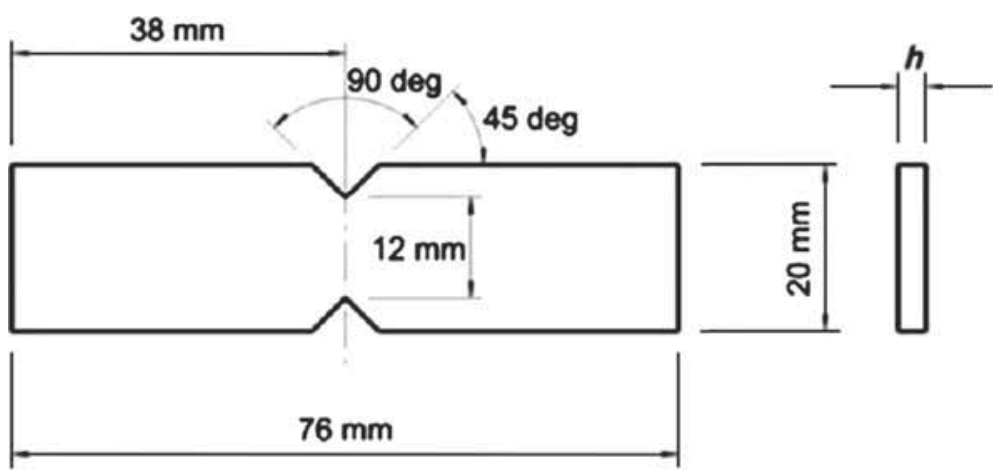

Figure 5. Double shear test specimen.

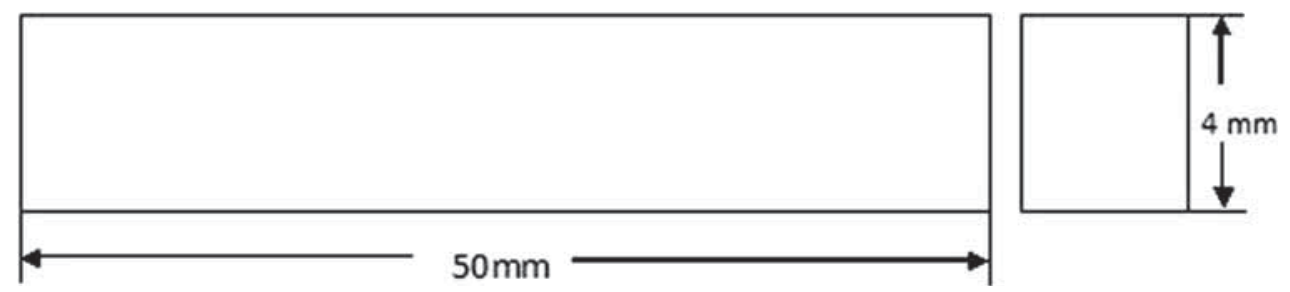

Figure 6. Inter-delamination test specimen.

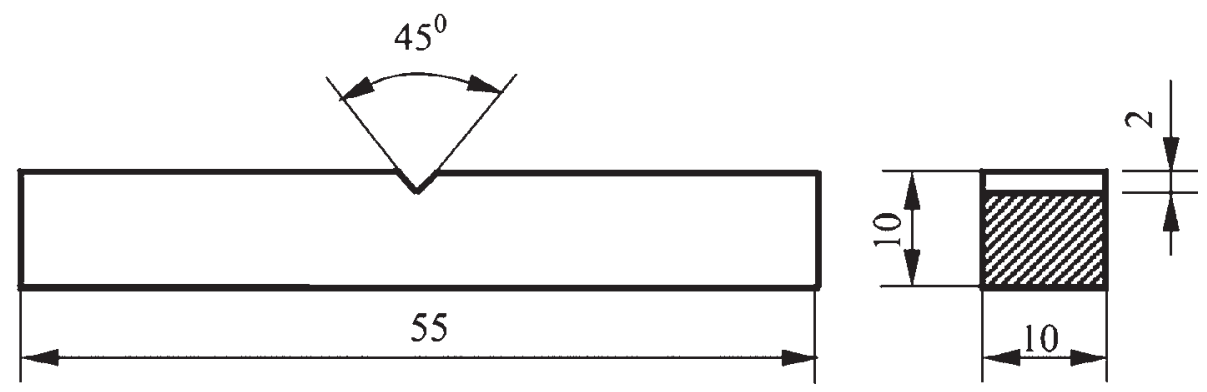

Figure 7. Impact test specimen.

$135^{\circ}$ to hit and fracture the specimen. In this work, ASTM: D256 standard is used to prepare the sample for conducting Charpy impact test as shown in figure 7. During testing, the amount of energy absorbed during breaking of the specimen is noted.

\section{Result and discussions}

\subsection{Type I (parallel orientation composite)}

4.1a Tensile test: The stress vs. stain comparison of tensile test for the three types of type I composite is shown in figure 8 . From the above graph, it is inferred that composite 3, which has a composition of abaca, neem and glass fibre has greater tensile strength than other two composites. This is because of the presence of the equal amount of abaca and neem fibre in the composite, which enables it to resist high tensile load during

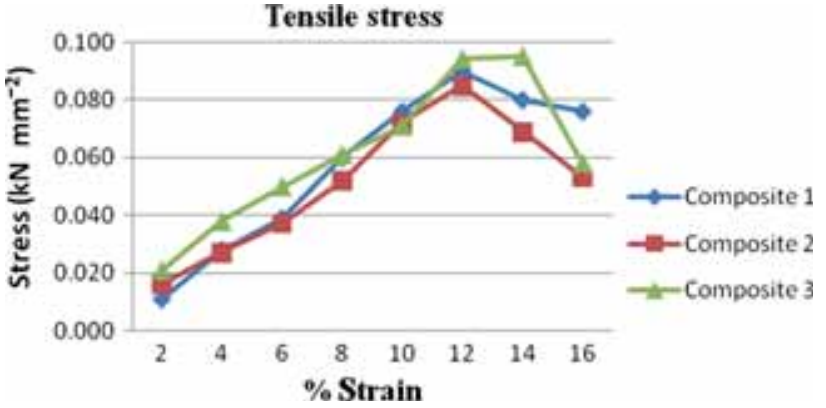

Figure 8. Result of tensile test—type I.

pulling. Moreover, high tensile modulus of abaca makes it to stand more load than other composites. It is observed that the yield stress of composite 3 is $0.096 \mathrm{kN} \mathrm{mm}^{-2}$ while for composite 1 is $0.081 \mathrm{kN} \mathrm{mm}^{-2}$. 


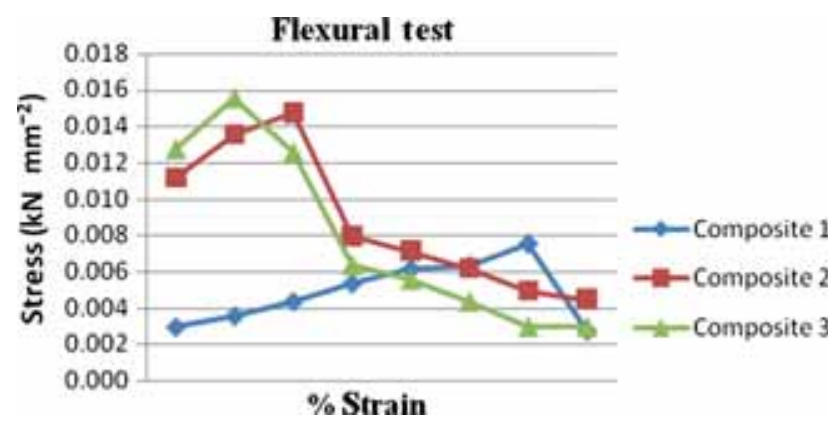

Figure 9. Result of flexural test—type I.

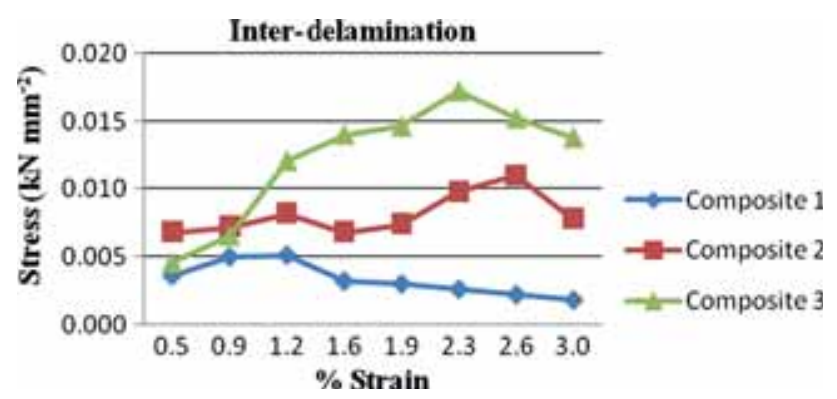

Figure 10. Result of inter-delamination test-type I.

4.1b Flexural test: The figure 9 shows stress $v s$. strain of flexural test of type I composite. From the above graph, it is clear that composite 3 has higher flexural strength than any other two composites. The flexural strength of composite 1 is much lesser than that of composites 2 and 3 . The composite 3 has the yield stress of $0.0159 \mathrm{kN} \mathrm{mm}^{-2}$.

4.1c Inter-delamination test: In composites and other layered materials delamination occurs due to cyclic stresses which lead to the separation of laminate from reinforcement. Figure 10 shows, stress vs. strain of inter-delamination for three composites. Composite 3 , has an equal amount of abaca and neem fibres, which results in delayed crack initiation. Owing to the presence of glass fibre with only neem and abaca fibre, composites 1 and 2 have less delamination strength than composite 3. This higher yield stress is due to the presence of higher quantity of abaca and neem fibre and also due to the arrangement of fibres in $90^{\circ}$ orientation, which makes the fibres to have continuous bonding on the entire layer.

4.1d Double shear test: The stress vs. strain of double shear test of type II composites is shown in figure 11. Like the other test, in this test also the composite 3 has a higher yield stress of $0.072 \mathrm{kN} \mathrm{mm}^{-2}$, which is due to the perpendicular orientation of fibre arrangement and owing to the presence of both fibres as well, which make the composite to resist the shear failure.

4.1e Impact test: Figure 12 shows the result of impact test of type I composite. From the graph it is clear that hybrid

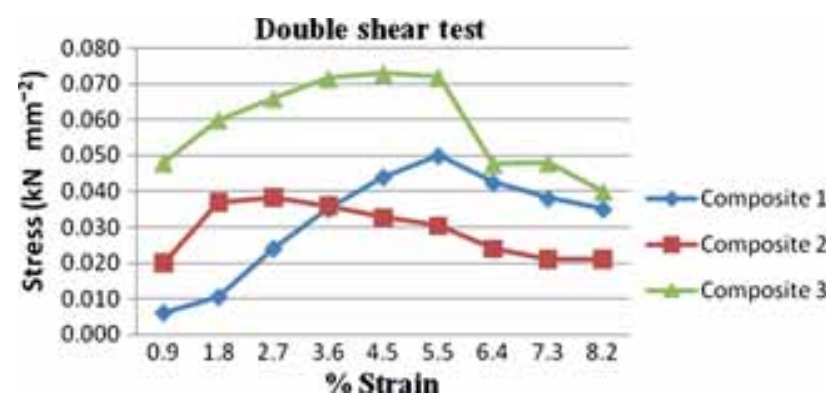

Figure 11. Result of double shear test-type II.

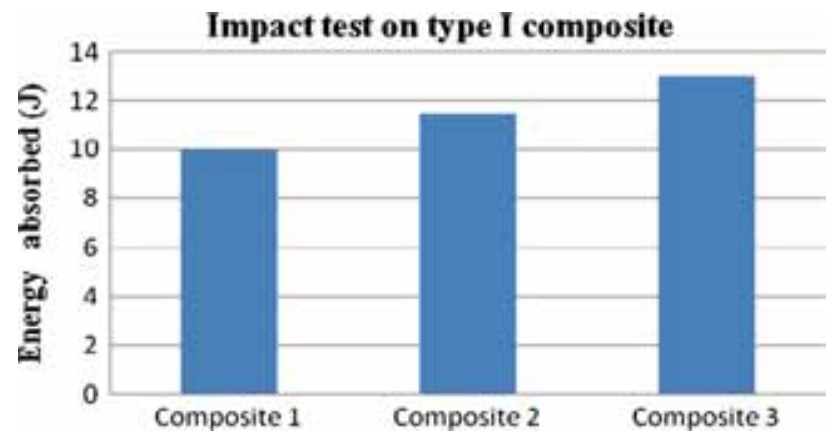

Figure 12. Result of impact test-type I.

composite 3 absorbs more energy than other composites because of the presence of equal quantity of abaca and neem fibre as compared to other composites. Since composites 1 and 2 contain only single fibres, their energy absorption capability is less than composite 3 .

Results of all the tests of type I composite is furnished in table 1. From table 1 it is clear that composite 3 has good mechanical properties as compared to the other two composites. This is because of the presence of both abaca and neem fibres, which increase the mechanical strength of the composite laminate. Moreover, the load carrying behaviour of both fibres combines together and increases the mechanical strength of composites.

It is concluded that tensile and flexural strengths of type-I composite are higher than Abaca and Jute hybrid composite with parallel orientation. This is due to the presence of the neem fibre along with abaca fibre. In addition, the parallel orientation increases the surface contact of fibres. Maximum tensile strength of abaca-neem hybrid composite is $94-102 \mathrm{MPa}$, whereas abaca jute hybrid composite is $54.66 \mathrm{MPa}$. Similarly, flexural strength of abaca-neem composite is 13-22 MPa, whereas abaca-jute composite is 3.684 MPa. Moreover, impact and double sheer behaviour of abaca-neem composite are better than abaca-jute composite [10].

\subsection{Result of type II composite ( $90^{\circ}$ orientation)}

In this section, the result of type II composites is discussed along with various test results. 
Table 1. Consolidated result of type I composite.

\begin{tabular}{lccccc}
\hline $\begin{array}{l}\text { Name of } \\
\text { composite }\end{array}$ & $\begin{array}{l}\text { Maximum tensile } \\
\text { stress }\left(\mathrm{kN} \mathrm{mm} \mathrm{m}^{-2}\right)\end{array}$ & $\begin{array}{l}\text { Maximum flexural } \\
\text { stress }\left(\mathrm{kN} \mathrm{mm}^{-2}\right)\end{array}$ & $\begin{array}{l}\text { Maximum double shear } \\
\text { stress }\left(\mathrm{kN} \mathrm{mm}^{-2}\right)\end{array}$ & $\begin{array}{l}\text { Maximum delamination } \\
\text { stress }\left(\mathrm{kN} \mathrm{mm}^{-2}\right)\end{array}$ & $\begin{array}{l}\text { Maximum energy } \\
\text { absorbed }(\mathrm{J})\end{array}$ \\
\hline Composite 1 & 0.083 & 0.0078 & 0.045 & 0.005 \\
Composite 2 & 0.086 & 0.0145 & 0.055 & 0.011 \\
Composite 3 & 0.091 & 0.0159 & 0.080 & 0.017 \\
\hline
\end{tabular}

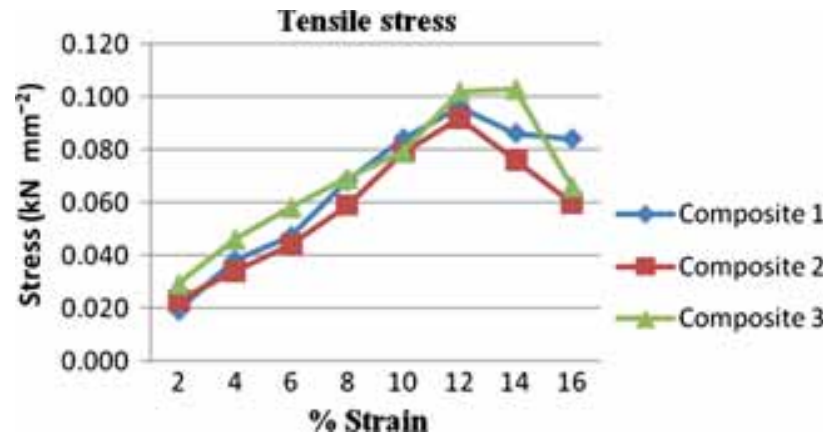

Figure 13. Result of tensile test-type II.

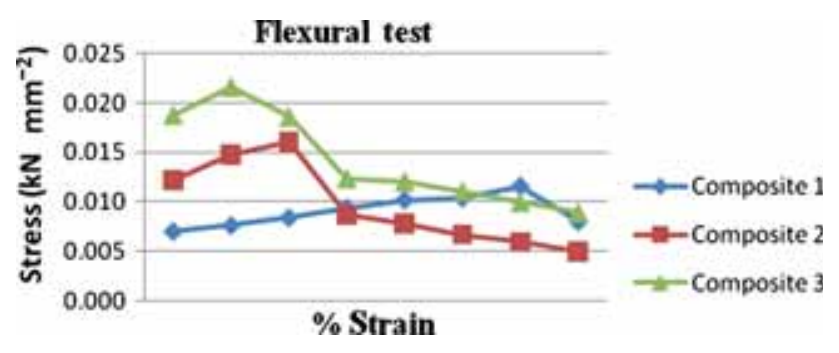

Figure 14. Result of flexural test-type II.

4.2a Tensile test: The results of the tensile test for three composites of type II is shown in figure 13. From the above graph, it is found that composite 3 , which has greater yield stress than the other composites is because of the presence of equal amounts of abaca and neem fibre. It is observed from the results that yield stress of composite 3 is $0.102 \mathrm{kN} \mathrm{mm}^{-2}$, which is comparatively more than tensile result of type I.

4.2b Flexural test: Figure 14 shows stress $v s$. strain of flexural test of the three composites. From the above graph it is found that composite 3 has the higher flexural stress of $0.021 \mathrm{kN} \mathrm{mm}^{-2}$, which is higher than type I composite. In addition, composite 1 withstands much lesser stress than that of composites 2, because in type II composite fibres are arranged at $90^{\circ}$ orientation that imparts sufficient strength to the composite against transverse bending during flexural test, which is not possible in case of type I composite.

4.2c Inter-delamination test: Figure 15 shows stress $v s$. strain of inter-delamination behaviour of three composites.

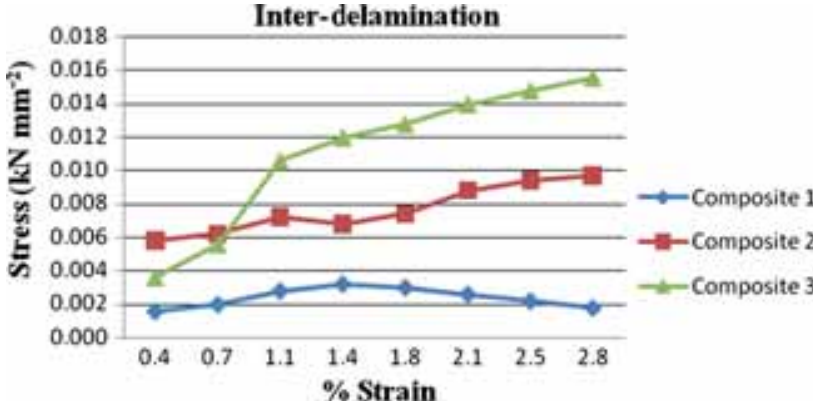

Figure 15. Result of inter-delamination test-type II.

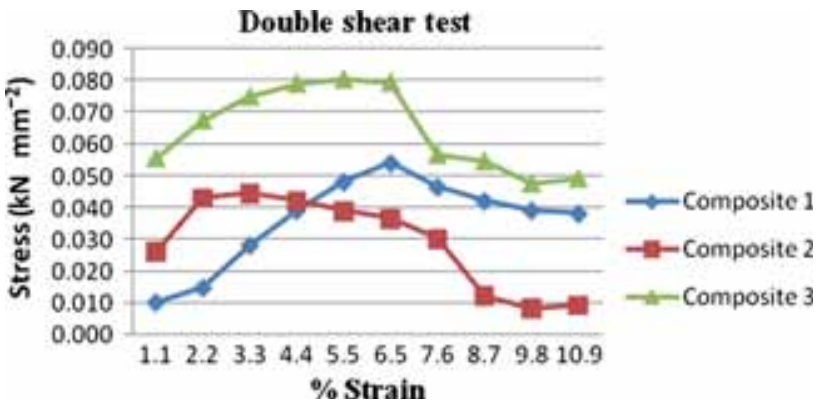

Figure 16. Result of double shear test-type II.

Similar to the tensile and flexural properties, here composite 3 shows higher yield stress of $0.0159 \mathrm{kN} \mathrm{mm}^{-2}$ as well.

4.2d Double shear test: Figure 16 represents stress vs. strain of double shear test. Like other properties, double shear behaviour of composite 3 is high as $0.080 \mathrm{kN} \mathrm{mm}$, which is more than the other two types of composites.

4.2e Impact test: Figure 17 shows the impact behaviour of type II composite. From the graph it is clear that composite 3 absorbs more energy due to hybridization of abaca and neem fibres.

Mechanical properties of all types of composites of type II is furnished in table 2. From this table it is evident that composite 3 shows better mechanical behaviour among its composites, which is the result of presence of both fibres in the laminate.

It is observed from table 2 that perpendicular orientation of fibre arrangement is having its impact on the strength of the composite. The tensile and flexural strengths of type II 


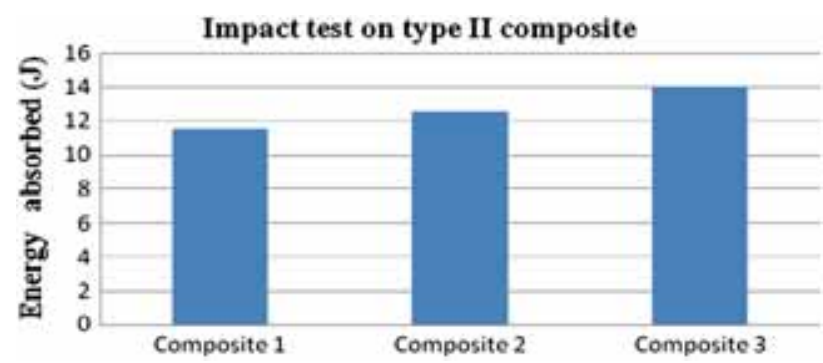

Figure 17. Result of impact test-type II.

composite made up of abaca-neem are higher than abacajute composites. It is found that abaca-neem composite has tensile strength of 83-91 MPa, whereas abaca-jute composite has $57 \mathrm{MPa}$ [28]. This is because of the presence of high tensile strength neem fibre in the composite. In addition, it is noted that flexural strength of abaca-neem composite is 7.815.9 MPa while abaca-jute composite shows $12.1 \mathrm{MPa}$, which is nearer to abaca-neem composite [28]. It was found that flexural strength of abaca-raffia composite is $9 \mathrm{MPa}$ as well, which falls in the same range of abaca-neem composite [29]. Moreover, impact and double shear behaviours of abaca-jute composite fall in the range of abaca-neem composite [28].

\subsection{Result of type III composite ( $45^{\circ}$ inclined orientation)}

4.3a Tensile test: Figure 18 shows, the stress vs. stain comparison of tensile test result for type III composite. From the above graph it is clear that composite 3, which has equal composition of abaca and neem fibre has greater yield stress than the other two composites. The yield stress of composite 3 is $0.1201 \mathrm{kN} \mathrm{mm}^{-2}$, which is comparatively more than the other types of composites. This is owing to the arrangement of fibres in $45^{\circ}$ inclined orientation, which in turn increases contact area between two layers of composite when compared with other two types. Moreover, fibre hybridization has its own effect on strength of the composite, which is clear from the test value.

4.3b Flexural test: The result of flexural test of the three composites is shown in figure 19. From the above graph, it observed that composite 3 has higher yield stress of $0.0265 \mathrm{kN} \mathrm{mm}^{-2}$ than composites 1 and 2 . From this it is

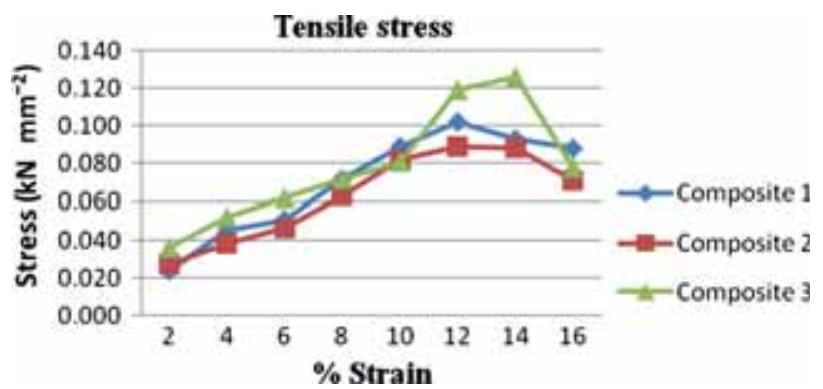

Figure 18. Result of tensile test—-type III.

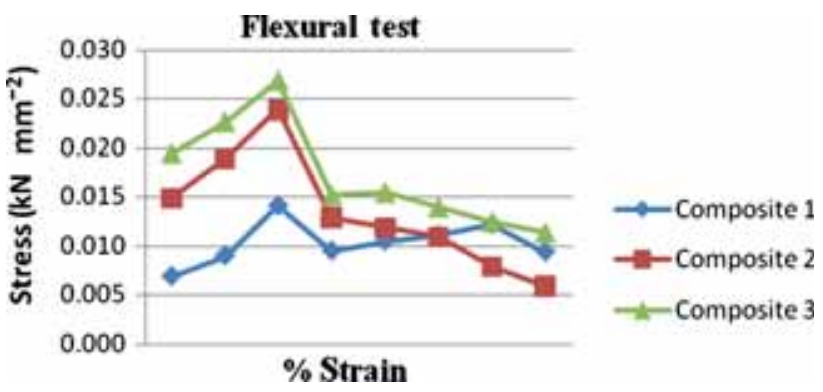

Figure 19. Result of flexural test-type III.

clear that hybridization of abaca and neem fibre with $45^{\circ}$ orientation resists the bending of the outer most layer of the composite laminate, which in turn results in high flexural strength of composite 3 than others.

4.3c Inter-delamination test: Stress vs. strain relation of inter-delamination test of composites is furnished in figure 20. Here, the composite 3 has a greater yield stress of $0.0175 \mathrm{kN} \mathrm{mm}^{-2}$, which is owing to the presence of the equal amount of abaca and neem fibre with $45^{\circ}$ inclined orientation that increases area of contact between fibres.

\subsection{Double shear test}

Figure 21 shows stress $v s$. strain of the double shear test of three composites of type III. The result shows that composite 3 has a maximum value of $0.082 \mathrm{kN} \mathrm{mm}$. This value is higher than other composites of type I, II and III. From this it can be concluded that fibres arranged in $45^{\circ}$ orientation will

Table 2. Consolidated result of type II composite.

\begin{tabular}{lccccc}
\hline $\begin{array}{l}\text { Name of } \\
\text { composite }\end{array}$ & $\begin{array}{l}\text { Maximum tensile } \\
\text { stress }\left(\mathrm{kN} \mathrm{mm} \mathrm{m}^{-2}\right)\end{array}$ & $\begin{array}{l}\text { Maximum flexural } \\
\text { stress }\left(\mathrm{kN} \mathrm{mm}^{-2}\right)\end{array}$ & $\begin{array}{l}\text { Maximum double shear } \\
\text { stress }\left(\mathrm{kN} \mathrm{mm}^{-2}\right)\end{array}$ & $\begin{array}{l}\text { Maximum delamination } \\
\text { stress }\left(\mathrm{kN} \mathrm{mm}^{-2}\right)\end{array}$ & $\begin{array}{l}\text { Maximum energy } \\
\text { absorbed }(\mathrm{J})\end{array}$ \\
\hline Composite 1 & 0.094 & 0.013 & 0.039 & 0.003 \\
Composite 2 & 0.092 & 0.016 & 0.050 & 0.008 & 0.016 \\
Composite 3 & 0.102 & 0.022 & 0.072 & 11.5 \\
\hline
\end{tabular}




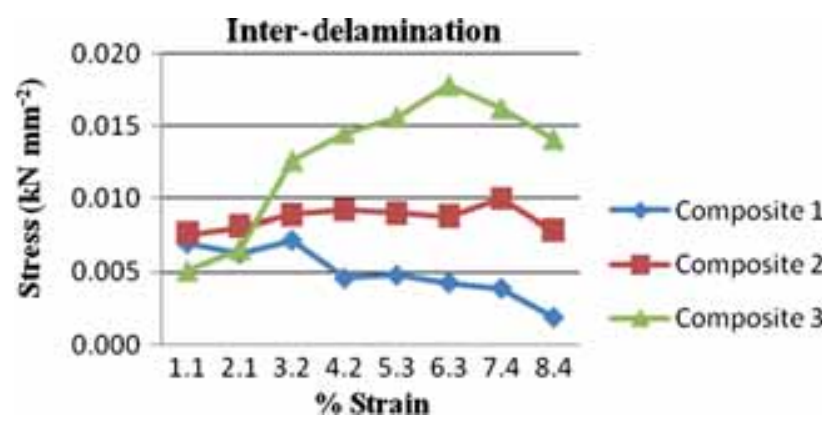

Figure 20. Result of inter-delamination test-type III.

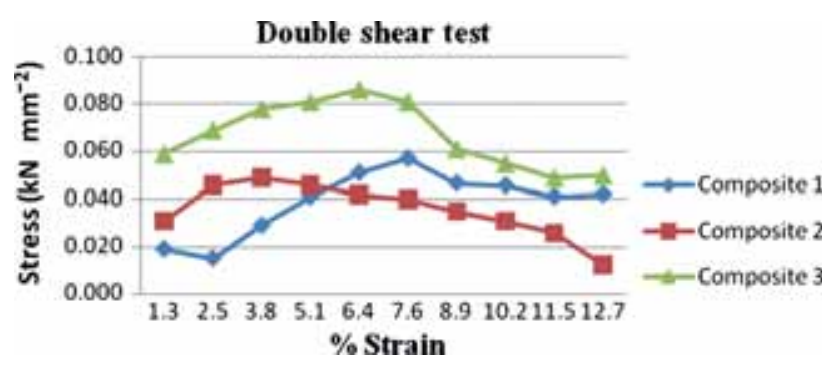

Figure 21. Result of double shear test-type III.

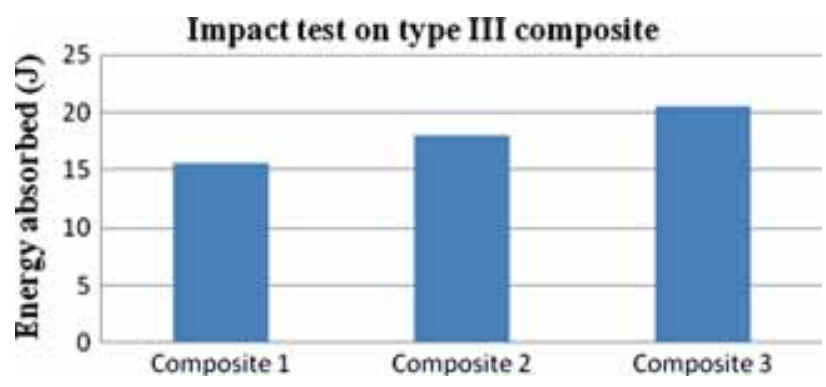

Figure 22. Result of impact test—-type III.

show good shear behaviour when compared with other two orientations.

4.4a Impact test: Figure 22 shows impact behaviour of type III composite from which it is clear that composite 3 absorbs more energy because of hybridization of abaca and neem fibre. It is also observed that fibres with orientation of $45^{\circ}$ increases the fibre density in the composite laminate in comparison with other two types, which helps in absorbing more energy.
From table 3 it is observed that composite 3 shows more flexural and de-lamination behaviour as compared to other composites. In addition, it shows that other properties namely tensile, double shear and impact strength are higher than other composites. This is because of the presence of abaca and neem fibre that are arranged in $45^{\circ}$ inclination. The inclined arrangement of fibre increases the contact area among fibres, which in turn improves all the mechanical properties of composites.

It is noted that tensile strength of type-III abaca-neem composite falls in the range of 90-120.1 MPa, although treated abaca polypropylene composite shows a maximum of $80 \mathrm{MPa}$ from which it is clear that reinforcement of neem increases the tensile behaviour of composite [27]. It is also clear that abaca-jute composite has tensile strength in the range of $47.83-70.25 \mathrm{MPa}$, which is less than the abaca-neem composite [10]. In addition, flexural strength of abaca-jute composite is less than abaca-neem composite, which is in the range of 14-26.5 MPa. Similarly, maximum energy absorbed by abaca-jute composite is $4.8 \mathrm{~J}$, whereas abaca-neem composite shows $20.5 \mathrm{~J}$.

\section{Morphological analysis}

Morphological analysis is done to analyse the internal surface characteristics of the tested composite samples using SEM. For conducting this analysis, the samples of various tests are dried and coated with $15-20 \mathrm{~nm}$ thick layer of gold with an ion sputter coating device. After that the specimens are inspected by SEM. The interfacial adhesion between matrix and the fibre is clearly seen from the scanning electron micrographs. Figure 23 shows the SEM image of tensile-tested specimen of composite 1. Fibre pull out and resin run out are observed in the image, which is because of improper layering of fibres during fabrication that results in composite breakage during initial loading. This can be solved by proper cleaning, combing and layering of fibres at the time of composite fabrication.

Figure 24 shows SEM image of flexural-tested specimen of composite 2. Resin block and accumulation is observed in the sample that results in fibre breakage and crack propagation. This can be avoided by proper mixing of resin and hardener, by giving proper curing time and placing weights on the composite.

Figure 25 shows internal fibre arrangement of impact-tested specimen of composite 3 . More number of cavities and fibre cracks are observed in the specimen, which results in the reduction in strength of the material. This can be avoided by proper distribution of resin hardener mixture.

Table 3. Consolidated result of type III composite.

\begin{tabular}{lccccc}
\hline $\begin{array}{l}\text { Name of } \\
\text { composite }\end{array}$ & $\begin{array}{l}\text { Maximum tensile } \\
\text { stress }\left(\mathrm{kN} \mathrm{mm}^{-2}\right)\end{array}$ & $\begin{array}{l}\text { Maximum flexural } \\
\text { stress }\left(\mathrm{kN} \mathrm{mm}^{-2}\right)\end{array}$ & $\begin{array}{l}\text { Maximum double shear } \\
\text { stress }\left(\mathrm{kN} \mathrm{mm}^{-2}\right)\end{array}$ & $\begin{array}{l}\text { Maximum delamination } \\
\text { stress }\left(\mathrm{kN} \mathrm{mm}^{-2}\right)\end{array}$ & $\begin{array}{l}\text { Maximum energy } \\
\text { absorbed }(\mathrm{J})\end{array}$ \\
\hline Composite 1 & 0.09 & 0.014 & 0.059 & 0.007 & 15.5 \\
Composite 2 & 0.100 & 0.023 & 0.040 & 0.009 & 0.018 \\
Composite 3 & 0.1201 & 0.0265 & 0.08 & 0.5 \\
\hline
\end{tabular}




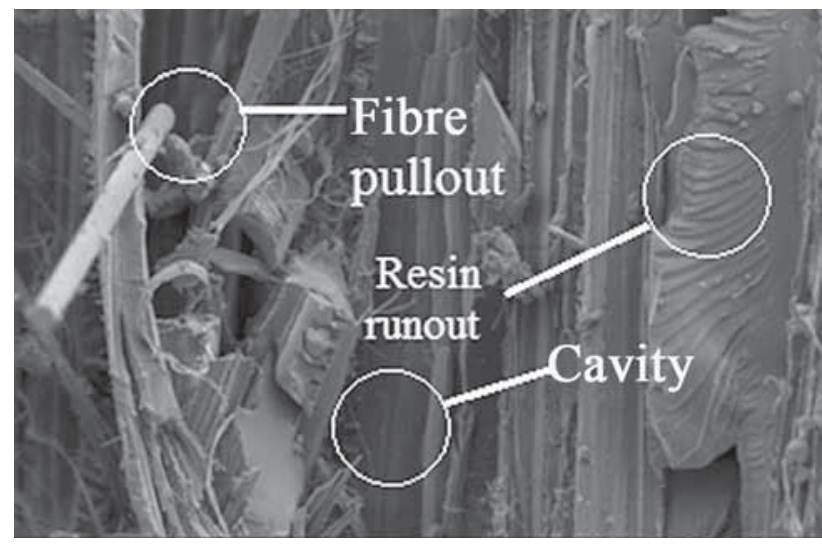

Figure 23. SEM image of tensile-tested composite 1.

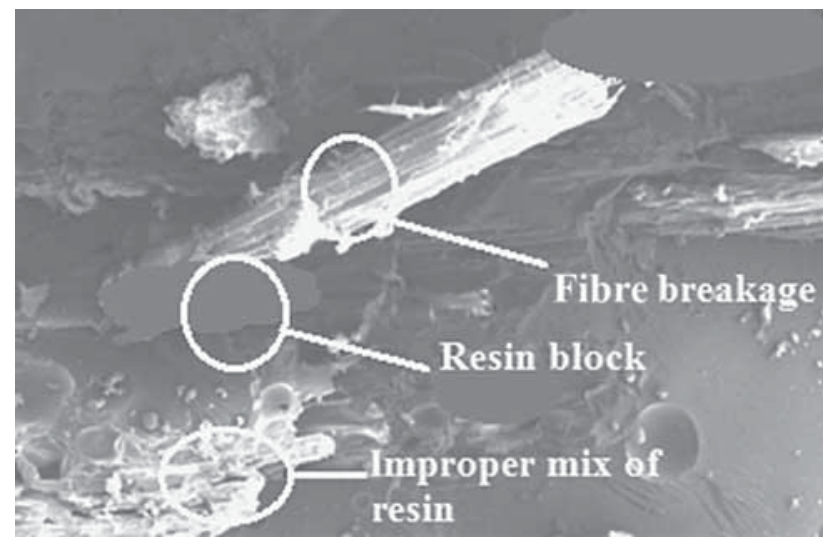

Figure 24. SEM image of composite 2.

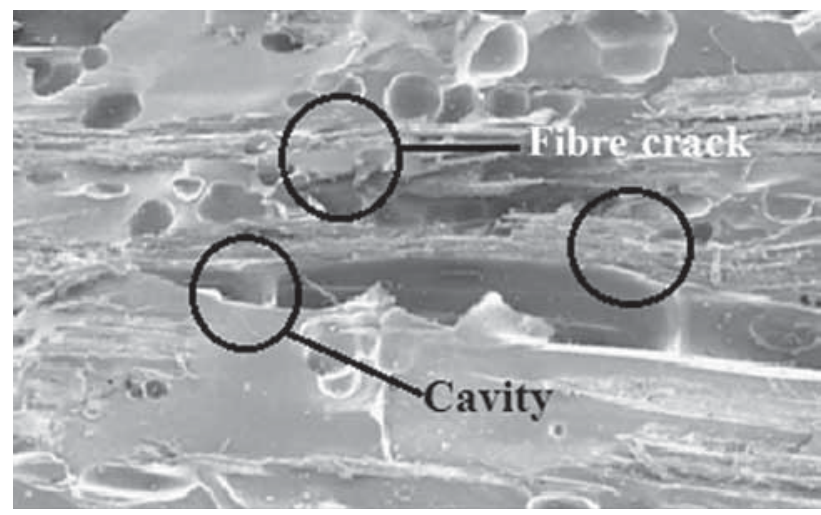

Figure 25. SEM image of composite 3 .

\section{Conclusion}

In this work, composites are fabricated with abaca, neem, and abaca + neem fibres and it is concluded that the hybrid composite consists of abaca and neem fibres, which give better mechanical properties than the other two. It is also concluded that fibres arranged in $45^{\circ}$ orientations have better mechanical properties than fibres in horizontal and vertical orientation.

\section{References}

[1] Sawsen C, Fouzia K, Mohamed B and Moussa G 2014 Constr. Build. Mater. 54659

[2] Liang S, Gning P-B and Guillauma L 2013 Int. J. Fatigue 63 36

[3] Sparnins E, Nystrm B and Andersons J 2012 Int. J. Adhes. Adhes. 3639

[4] El-Shekeil Y A, Sapuan S M, Jawaid M and Al-Shuja O M 2013 Mater. Des. 58130

[5] Sawpan M A, Pickering K L and Fernyhough A 2010 Mech. Mater. 124

[6] Mahjoub R, Yatim J M, Sam A R M and Hashemi S H 2013 Constr. Build. Mater. 55103

[7] Anuar H and Zuraida A 2011 Composites Part B 42462

[8] Sapuan S M, Leenie A, Harimi M and Beng Y K 2006 Mater. Des. 27689

[9] Hamzaoui R, Guessasma S, Mecheri B, Eshtiaghi A M and Bennabi A 2014 Mater. Des. 5660

[10] Vijaya Ramnath B, Manickavasagam V M, Elanchezhian C, Vinodh Krishna C, Karthik S and Saravanan K 2014 Mater. Des. 60643

[11] Pothana L A, Zachariah Oommen B and Sabu Thomas C 2003 Compos. Sci. Technol. 63283

[12] Li Z, Wang X and Wang L 2006 Composites 37497

[13] Aziz S H and Ansell M P 2004 Compos. Sci. Technol. 641219

[14] Sellamia A, Merzouda M and Amzianeb S 2013 Constr. Build. Mater. 471117

[15] Azwa Z N, Yousif B F, Manalo A C and Karunasena W 2013 Mater. Des. 47424

[16] Ravi Sankar M, Lava Kumar M and Haribabu S 2014 Int. J. Eng. Trends Technol. 173

[17] Moothoo J, Allaoui S, Ouagne P and Soulat D 2014 Composites $\mathbf{5 1} 764$

[18] Bledzki A K, Jaszkiewicz A and Scherzer D 2009 Composites Part A 40404

[19] Rahman Md R, Huque Md M, Islam Md N and Hasan M 2009 Compos. Part A: Appl. Sci. Manuf. 40511

[20] Liu K, Takagi H, Osugi R and Yang Z 2012 Compos. Part A: Appl. Sci. Manuf. $\mathbf{4 3} 1234$

[21] Liu K, Zhang X, Takagi H, Yang Z and Wanga D 2014 Composites 66227

[22] Bledzki A K, Mamun A A, Jaszkiewicz A and Erdmann K 2010 Compos. Sci. Technol. 70854

[23] Gironès J, Lopez J P, Vilaseca F, Bayer J, Herrera-Franco P J and Mutjé P 2011 Compos. Sci. Technol. 71122

[24] Vijaya Kumar T, Ramana K V, Bala Murali K V and Shahjahan P 2012 Gold. Res. Thoughts 21

[25] Ali Md A, Suman K N S and Kesava Rao V V S 2012 Glob. J. Res. Eng. Mech. Mech. Eng. 121

[26] Mike G R, Smith O O and Stanley A O 2016 Int. J. Adv. Res. 4155

[27] Punyamurthy R, Sampathkumar D, Ranganagowda G, Bennehalli B and Srinivasa V J 2015 King Saud Univ. Eng. Sci. (in press)

[28] Vijaya Ramnath B, Niranjan Raja R, Junaid Kokan S, Sathya Narayanan R, Rajendra Prasad A R and Elanchezhian C et al 2013 Mater. Des. 51357

[29] Sathish P, Kesavan R and Vijaya Ramnath B 2015 J. Eng. Appl. Sci. 1013 